\title{
Investigation of the effect of protective crown roughness on reduction of scouring depth River candles using Flow 3D software
}

\author{
Mohammad rafie rafiee, Roozbeh Aghamajidi, Sajad Amiri \\ Professor Assistant, water engineering Department, \\ Agriculture Faculty, Jahrom university, Jahrom ,iran \\ email: mrrafiee73@gmail.com, \\ Professor Assistant, Civil engineering Department, \\ Islamic azad university, Sepidan Branch, Sepidan , Iran \\ email: roozvbeh1381@yahoo.com \\ Msc of Hydraulic Structure ,Islamic azad university, Shoshtar Branch ,Shoshtar, Iran \\ email: sajjadamiri1987@gmail.com
}

\begin{abstract}
Scouring, (Water erosion) and its impact is one of the most important and, of course, common phenomena in the field of hydraulic structures. The use of equipment such as crowns is very effective in controlling the scour and has many different forms. In this study, the effect of full crown roughness on the scour around the bridge support was investigated. Variable and influential parameters in the experiments were determined using dimensional analysis and it was determined that the scour function is a function of parameters such as $L_{\mathscr{C}} \mathrm{L}_{\mathrm{a}}, B_{\mathrm{d}} \mathcal{L}_{\mathrm{a}}$ and $B_{\mathrm{u}} \mathcal{L}_{\mathrm{a}}$. The parameters and variables used in the practical experiments were modeled using Flow-3D software. In other words, the placement of rough crowns in the upper levels of the bed performs is better than smooth crowns. In surface and subsurface crowns, due to the low space between the crown and the sediment, crown roughening does not have a significant effect on crown yield, although the use of rough crown instead of smooth crown reduces scour by approximately $22 \%$.
\end{abstract}

Keywords: Flow-3D software, Scouring (Water erosion), Crown.

\section{Introduction}

Scouring or (Water erosion), is one of the most important issues in hydraulics, river engineering and beaches. Bridge piers, oil rigs, gutters and underground pipes are among the most important structures that threaten the risk of flooding. Scouring or (Water erosion), around the pier of bridges is one of the most important topics in hydraulic science. Occurrence of local scour around the pier and abutment of bridges is one of the major causes of bridge failure. The scouring or (Water erosion) around bridges has been the focus of much more research on the pier than the abutment, while a review of existing statistics on the bridges failure shows that most of the problems are related to the abutment, and therefore more costs have been spent on this part. Evaluation of the stream lines around these structures and such cases have been important issues for the researchers. Scouring (Water erosion), is a natural phenomenon that occurs by the interaction of water with sediment and bed material. Therefore, the depth of scouring (Water erosion), depends on these flow characteristics, bed material, geometrical dimensions of the bridge and foundation. It should be noted that the final depth of scour adjacent to the bridge pier will be equal to the sum of the erosion depths due to local and general scouring (Water erosion), and narrowing of flow width (contraction flow). Researchers have proposed a number of methods to prevent and reduce scouring (Water erosion), around the bridge pier, using gabion, submerged vanes, protective piles, slot and crowns. Designers should be aware of the maximum depth of scouring, the geometry and shape of the scouring hole to secure the structure against damage. In this study, the necessity of applying protective crowns and roughness parameter on them is investigated in depth scour changes around bridge pier. One way to reduce scour around the pier and bridge support is to install crowns on it. The crowns protect the bed against eddy currents around the pier. The collar is a thin plate mounted at a specified level from the pier of the bridge, thereby preventing direct downward contact of the bridge with the canal bed, reducing the activity of the horseshoe vortex as well as in the collar pier. Scour velocity is reduced or in other words, delayed the time of scour initiation (Nohani et al, 2012). Submerged vanes with eddy currents cause changes in the bed load movement regime and consequently change the deposition and erosion location (Fig.1). (Singh et al.,2001) reported that crowns with diameters of 1.5, 2 and 2.5 times the pier diameter on the channel bastards by 50,68 , and $100 \%$ reduced the scour relative to the unshielded pier, respectively. A review of the sources revealed that no comprehensive laboratory research has been conducted so far. Zarrati et al. (2004) performed numerous experiments on the application of collar to scour control in angular rectangular piers. The results of their experiments showed that larger collars were more effective at lower levels and that the efficiency of collars decreased with increasing pier angle relative to current. Scientists (2004) found that the collar, with dimensions about three times the pier of the rectangle on the bed, worked best and reduced 
the scour depth by up to $60 \%$. Ghorbani et al. (2008) investigated the effect of single and double Submerged vanes in reducing the scour of bridge foundations in vitro. They concluded that the use of two Submerged vanes was more effective in reducing the depth of scour than one. Arianfar et al. (2016) studied numerical simulation of flow pattern and prediction of local scour around circular bridge pier with slit protection and Submerged vanes using Flow-3d software. The results showed that the numerical model is in good agreement with the physical model and using these methods has a good effect on reducing the scour so that the use of slotted pier and Submerged vanes reduced the maximum depth of scour by about $32 \%$.

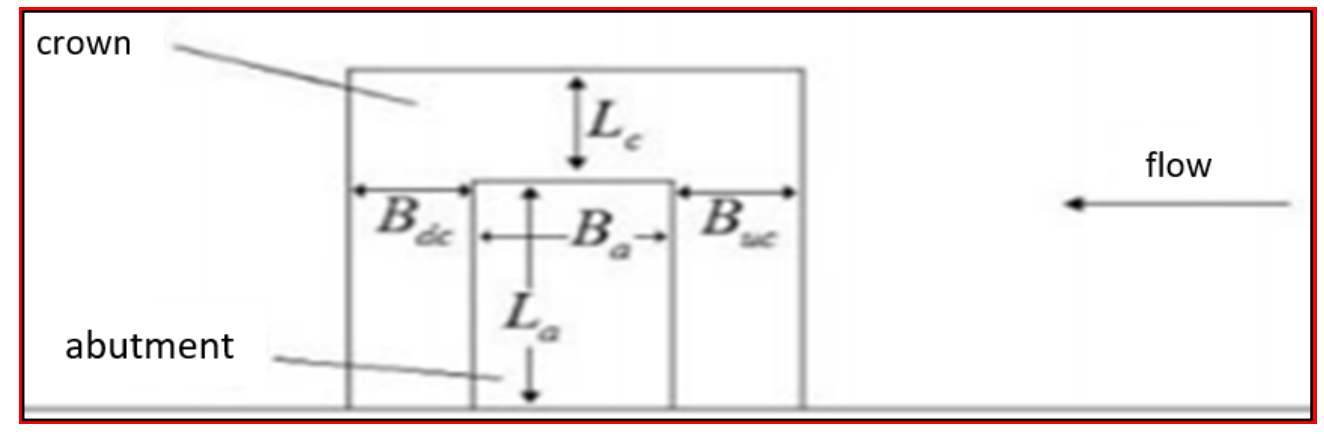

Fig 1. Crown schematics (plan)

\section{Materials and Methods}

In this research, by using Flow-3D software, numerical investigation of the three-dimensional turbulent flow field around a bridge has already been carried out. This study is further aimed at determining the extent of scour in a situation where the bridge foundations are reticulated by rectangular fringes, and the effect of this networking on the bridge pier is investigated at increasing or decreasing scour rates. Flow-3D software using Computational Fluid Dynamics (CFD) in 3D environment is able to predict free-surface fluid flow and perform hydraulic simulations and produce acceptable solutions in this field has done. The governing equations are known as NavierStoke 3D equations. These equations, which represent the flow velocity, are obtained from the equilibrium forces on a small volume of water in the laminar flow. Then the Reynolds mean method is used to convert them to turbulent flow. The equations used in this model include the principle of mass survival and motion size. The equation solving methods in this software are based on the finite volume method. As we know, the time-averaged equations are used to account for the effects of turbulence in the processes associated with turbulence. Therefore, continuity equations and momentum equations are used. In order to solve the turbulent flow field, it is necessary to model Reynolds stresses in the equations in a particular way. In this case, in the three-dimensional flow state, with four equations (one continuum and three moments), four unknowns of the current field (i.e. velocities in the $\mathrm{x}$ direction, $\mathrm{y}$ direction, $\mathrm{z}$ direction, and pressure) are determined. Turbulence models are used to express Reynolds stresses, or better to close the system of equations above. To this end, different turbulence models with varying degrees of complexity and capability are presented. After preparing the modeling steps in the software environment, it is time to extract the results from the software environment where the modeling results can be presented graphically and table.

\section{Dimensional Analysis}

The parameters affecting the amount of scour around the cradle supported by the crown are as follows:

$$
f\left(\mathrm{~B}, \mathrm{~L}_{\mathrm{a}}, \mathrm{B}_{\mathrm{a}}, \varphi_{1}, \mathrm{~L}_{\mathrm{c}}, \mathrm{B}_{\mathrm{uc}}, \mathrm{B}_{\mathrm{dc}}, \mathrm{Z}_{\mathrm{c}}, \varphi_{2}, \mathrm{~d}_{\mathrm{s}}, \mathrm{y}_{\mathrm{s}}, \mathrm{y}_{\mathrm{sc}}, \mathrm{Q}(\mathrm{V}), \mathrm{g}, \mathrm{y}, \alpha, \rho, \rho_{\mathrm{s}}-\rho, \mu\right)=0
$$

In equation (1), $B$ (channel width), $L_{a}$ (abutment length), $B_{a}$ (an anchor width), $\varphi_{1}$ (abutment shape factor), $L_{c}$ (Propulsion in width in the upstream of abutment), $B_{d c}$ (Propulsion in width in the downstream of abutment), $Z_{c}$ (crown vertical distance to fixed bed), $\varphi_{2}$ (crown shape factor), $d_{s}$ (sediment diameter), $Y_{s}$ and $Y_{s c}$ (scouring depth with and without crown respectively, since maximum scour depth without crown presence in upstream corner of the support therefore occurred for this point. Scour depth data collection was considered as the datum point in all experiments with crowns), Q or V are (discharge or velocity), g (gravity acceleration), y (flow depth), $\alpha$ (angle with the support of deal flow), $\rho$ (density of flow), $\rho_{\mathrm{s}}-\rho$ (submerged particle sediment density) and $\mu$ (dynamic viscosity coefficient). By applying Buckingham's theory, equation (1) will become equation (2).

$$
\mathrm{P}_{\mathrm{r}}=f\left(\mathrm{~L}_{e} \mathrm{~L}_{\mathrm{a}}, \mathrm{B}_{\mathrm{u} d} \mathrm{~L}_{\mathrm{a}}, \mathrm{B}_{\mathrm{d} d} \mathcal{L}_{\mathrm{a}}, \mathrm{Z}_{\complement} \mathcal{y}, \mathrm{F}_{\mathrm{r}}, \mathrm{L}_{\mathrm{a}} \mathrm{B}, \mathrm{L}_{\mathrm{a}} \mathrm{B}_{\mathrm{a}}, \mathrm{d}_{\mathrm{s}} / \mathrm{y}, \mathrm{G}_{\mathrm{s}}, \mathrm{R}_{\mathrm{e}}, \alpha, \varphi_{1}, \varphi_{2}\right)
$$

In equation (2), Pr (percentage of scour depth decrease that is extracted from equation (3)), Fr (Froude number), Gs (sediment density), and Re (Reynolds number), and other parameters are already defined.

$$
\operatorname{Pr}=\left(\left(\mathrm{y}_{\mathrm{s}}-\mathrm{y}_{\mathrm{sc}}\right) / \mathrm{y}_{\mathrm{s}}\right) * 100
$$

Among the dimensionless parameters in equation (3), $\mathrm{B}_{\mathrm{u} e} \mathrm{~L}_{\mathrm{a}}, \alpha, \varphi_{1}, \varphi_{2} \mathrm{Z}_{\complement} / \mathrm{y}, \mathrm{F}_{\mathrm{r}}, \mathrm{L}_{\mathrm{a}} \mathrm{B}, \mathrm{L}_{\mathrm{a}} \mathrm{B}_{\mathrm{a}}, \mathrm{d}_{\mathrm{s}} \mathrm{y}, \mathrm{G}_{\mathrm{s}}$, were considered constant and were therefore deleted. The Reynolds number was also tested and deleted in all experiments to ensure turbulent flow $(\operatorname{Re}>2000)$. evaluated values of the Dimensional parameters. 
Table 1. Dimensionless parameters and values examined

\begin{tabular}{|c|c|}
\hline the values evaluated & Dimensional parameter \\
\hline $0.75-0.25$ & $\mathbf{L}_{\mathbf{c}} / \mathbf{L}_{\mathbf{a}}$ \\
\hline 0.5 & $\mathbf{B}_{\mathbf{u c}} / \mathbf{L}_{\mathbf{a}}$ \\
\hline $0.5-0.25$ & $\mathbf{B}_{\mathbf{d c}} / \mathbf{L}_{\mathbf{a}}$ \\
\hline
\end{tabular}

Results and Discussion

In the present study, numerical modeling was used to investigate the influence of crown presence conditions (rough and smooth) around the bridge pier and also without crown. Figure 2 shows the performance of a smooth crown with a bridge pier.

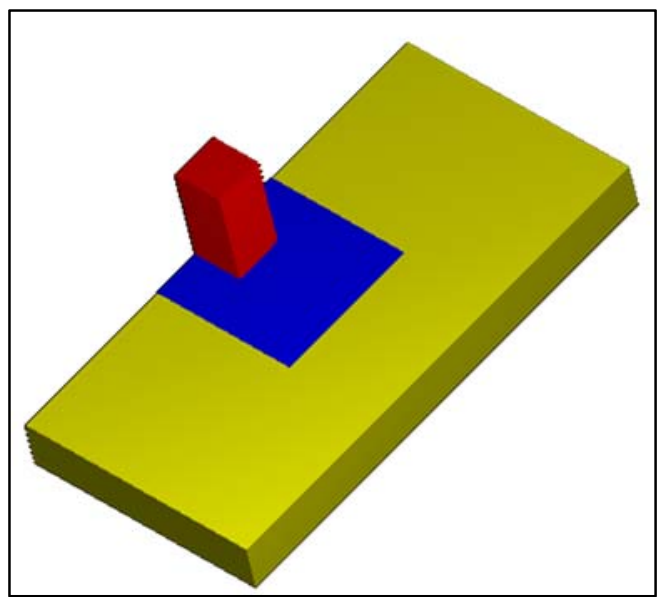

Fig 2. The presence of a smooth crown and bridge pier

Investigation of change of scour geometry against roughness change at crown surface:

We first carried out the necessary investigations while the pier of the bridge without the crown is in the flow direction. In this case, the onset of scour was from the upstream corner of the support, initially increasing the scour depth rapidly, so that in the early modeling times about 70 to $80 \%$ of the scour depth occurs, then the scour gradually decreases. At the final stage of modeling, very little is added to the scour depth. During the run of the sediment model, the scour hole wall was drilled into the pit and then transported into the downstream sediment stack. The sedimentary ridge gradually moves downstream, thus extending the scouring hole development over the modeling period.

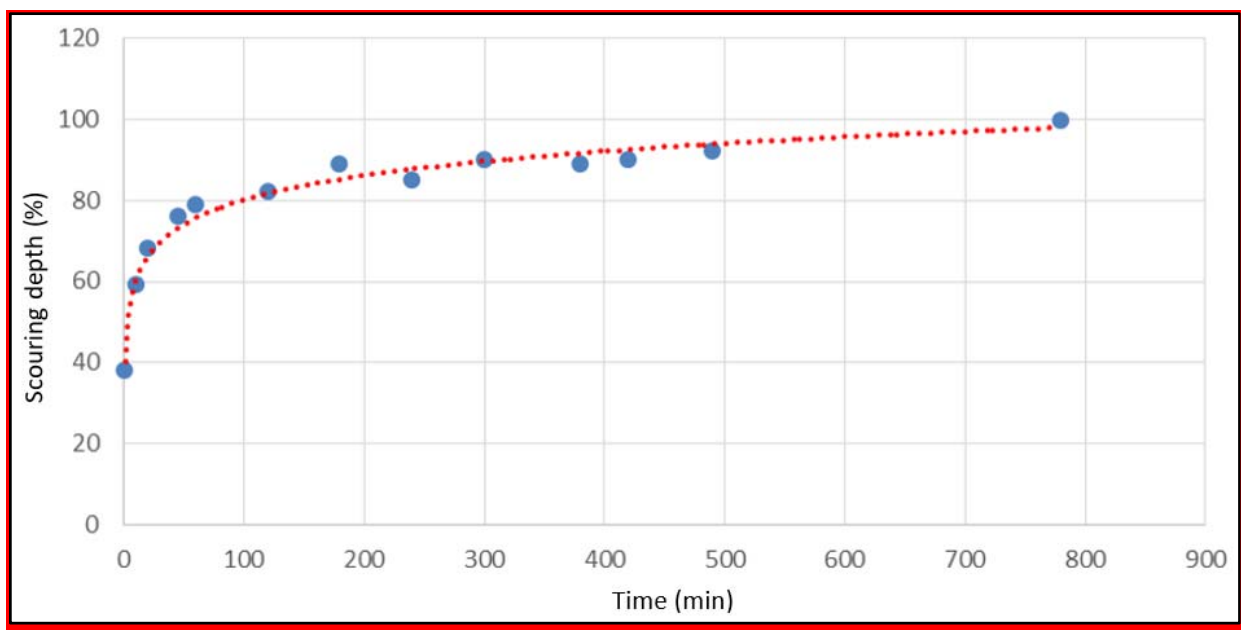

Fig 3. Changes in the depth of scour vs. time in the absence of crowns

$1 \mathrm{~mm}$ fractions were used to create the roughness on the crown surface Figure (4a), while Figure (4b) shows the roughness created after polishing in the numerical model and Figure (5), Is also present. Sharp crown around the pier of the bridge. 


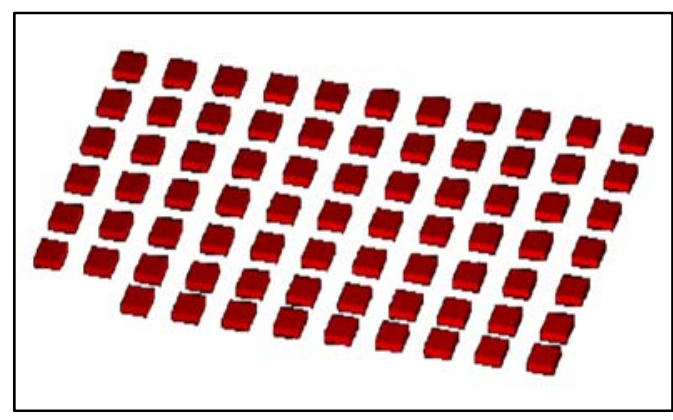

A) $1 \mathrm{~mm}$ dimension

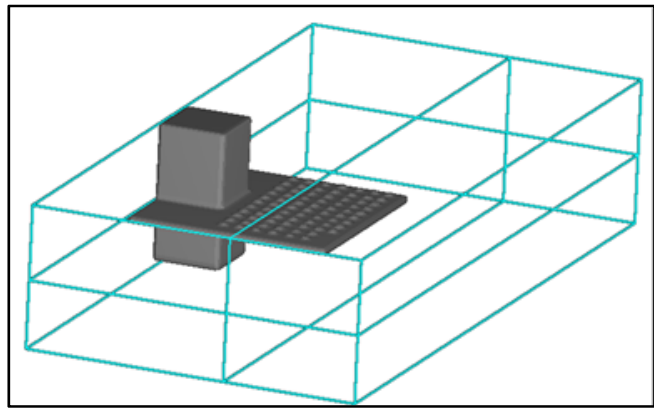

b) roughness on the crown surface

Fig 4. Modeling of friction and roughness on crown surface

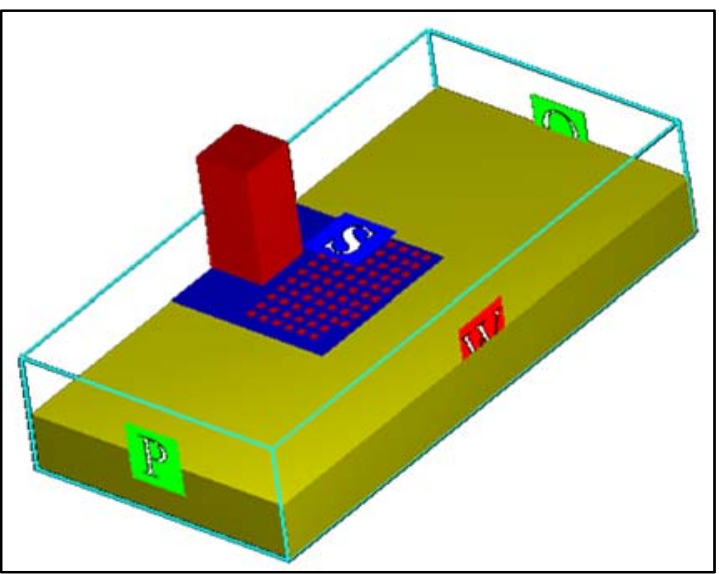

Fig 5. The presence of rough crown around the pier of the bridge
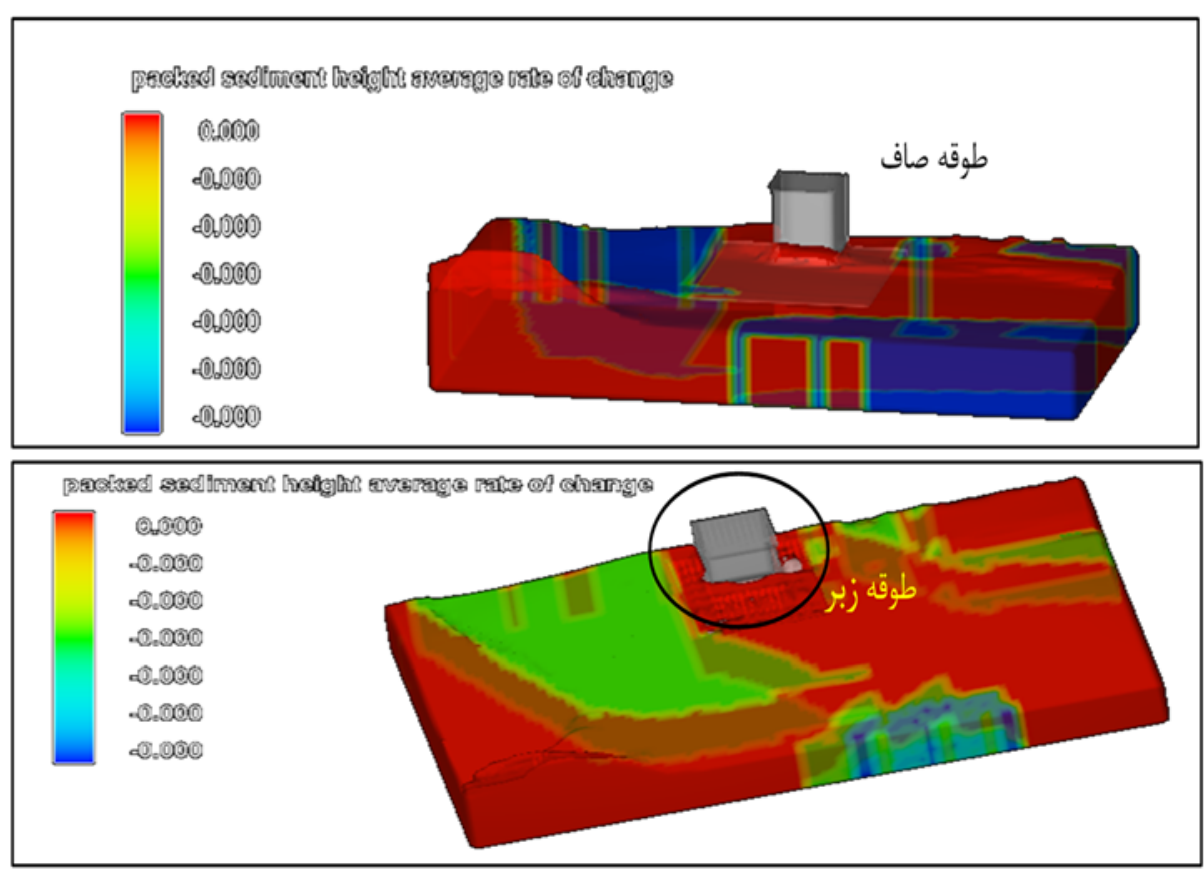

Fig 6. Start of modeling at zero time and scour changes around bridge pier with smooth crown

It can be seen in Figure (6) that by roughening the crown bed, the scour depth is significantly reduced, and this depth reduction is assumed to be the same for both plates.

It can be seen in Figure (7) that in the initial values of the ratio $(\mathrm{Zc} / \mathrm{y})$, the maximum scour occurs and gradually decreases with increasing slope $(\mathrm{Zc} / \mathrm{y})$. 


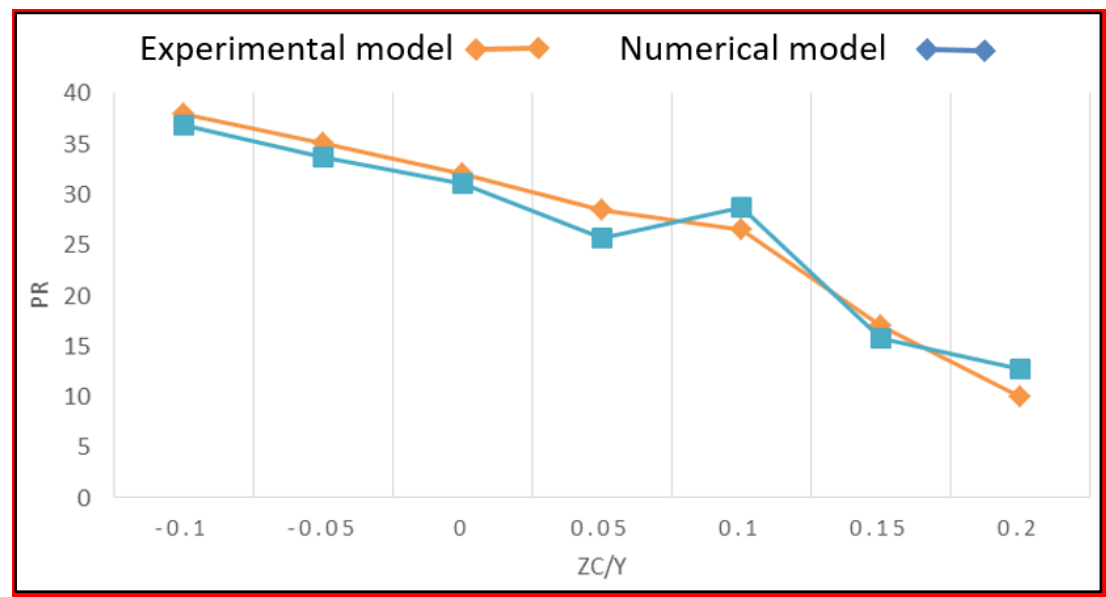

Fig 7. Comparison of numerical and laboratory modeling results in the presence of a smooth crown

As shown in Figure (8), the crown will be affected by rough conditions, and the condition of these crowns is almost different from that of smooth crowns, so that when the crown is roughened at different $\mathrm{Zc} / \mathrm{Y}$ ratios, the reduction of the scour rate is greater. will be. However, with the presence of crowns under the bed, no significant difference in the performance of the two types of smooth and coarse crowns was observed.

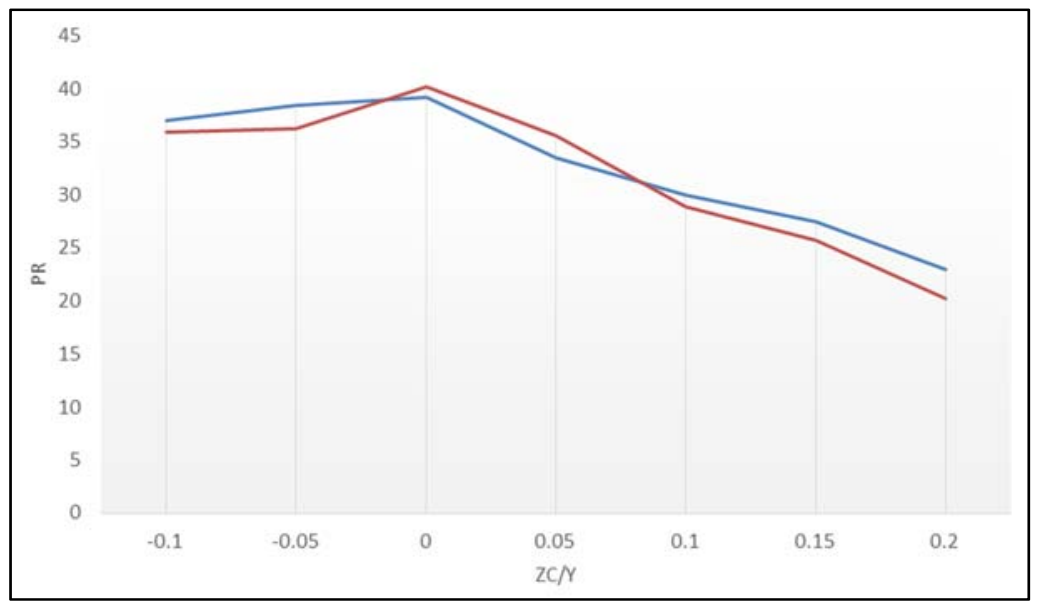

Fig 8. Comparison of numerical and laboratory modeling results in the presence of rough crown

According to Figure (9), at a smooth surface the boundary layer expands rapidly and the separation point occurs at a distance closer to the beginning of the surface than the rough surface, after which the separation point forms a rotational and vortex flow. In this study, it seems that due to the smoothness of the crowns, the presence of vortices influences the scouring rate.

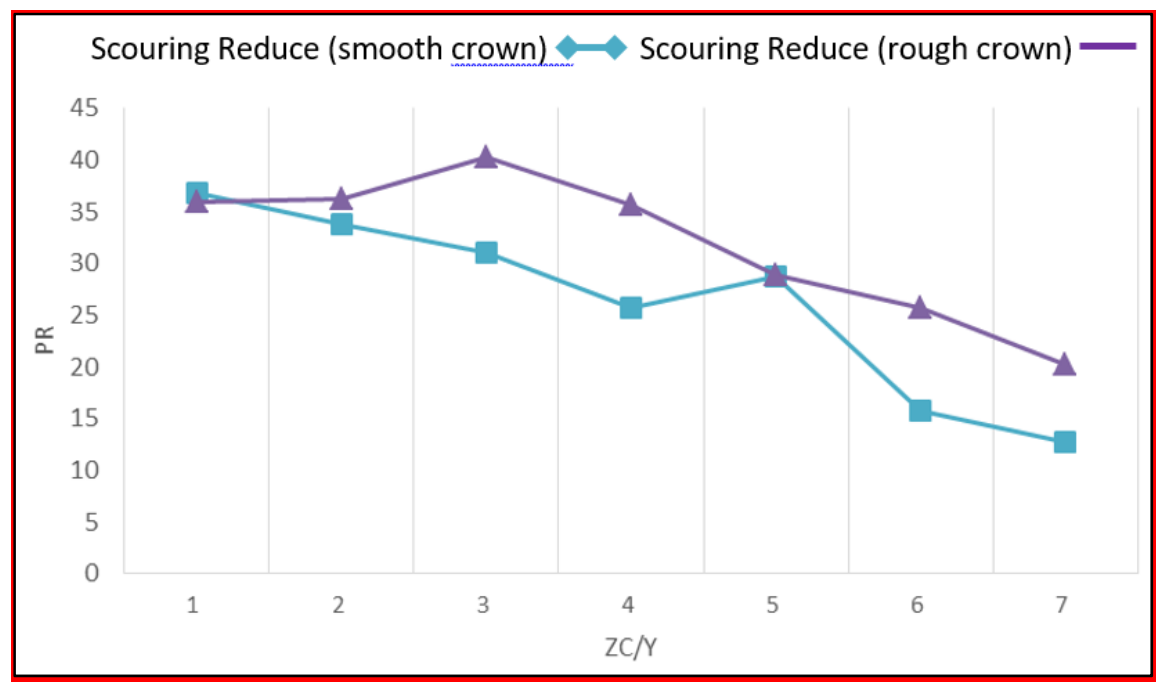

Fig 9. Comparison of numerical model results in rough crown mode 
Table 2. Comparison of scour depth reduction in the presence of rough and smooth crowns

\begin{tabular}{|c|c|c|}
\hline$Z_{\mathrm{c}} / \mathrm{y}$ & $\begin{array}{c}\text { scouring depth reduce percentage } \\
\text { (smooth crown) }\end{array}$ & $\begin{array}{c}\text { scouring depth reduce percentage } \\
\text { (rough crown) }\end{array}$ \\
\hline$-0 / 1$ & $36 / 78$ & $35 / 89$ \\
\hline$-0 / 05$ & $33 / 69$ & $25 / 36$ \\
\hline 0 & $30 / 98$ & $40 / 2$ \\
\hline $0 / 05$ & $25 / 64$ & $35 / 6$ \\
\hline $0 / 1$ & $28 / 65$ & $28 / 9$ \\
\hline $0 / 15$ & $15 / 78$ & $25 / 669$ \\
\hline $0 / 2$ & $12 / 65$ & $20 / 156$ \\
\hline
\end{tabular}

It can be seen from Figure (10) that in the absence of crowns, the scour will approach the pier of the bridge and create critical conditions for the pier of the bridge. It should be noted that damages to the pier are high risk due to the risk of scour, while in addition to increasing the depth of the scour, the scour profile will also move to the pier of the bridge.

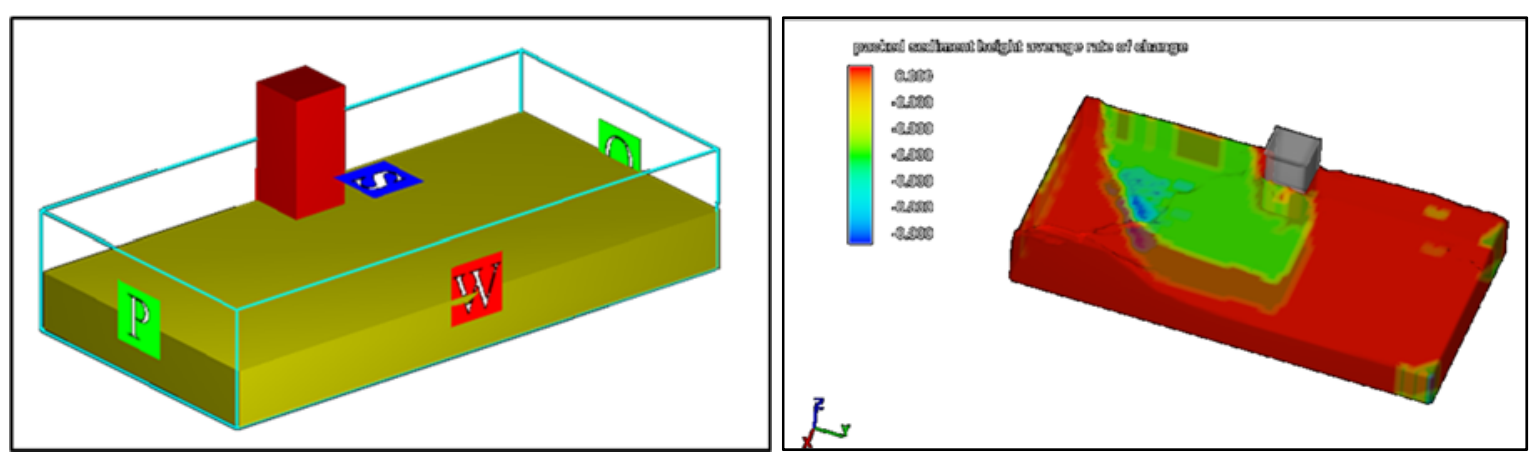

Fig 10. Examination of scour phenomenon around bridge pier in absence of crown

Table 3 shows the results of the scour reduction in all available cases. On average, the increase in the reduction in scour is about $22 \%$. In other words, this can be dramatically improved by using rough plates around the pier of the bridge as crowns.

Table 3. Mean values of scour depth decrease in smooth and rough states

\begin{tabular}{|c|c|c|c|}
\hline Depth Percent (smooth crown) & Depth (rough crown) & Percent of Change & Type of Change \\
\hline 36.78 & 35.89 & 2.43 & Decrease \\
\hline 33.69 & 36.25 & 7.04 & Increase \\
\hline 30.98 & 40.2 & 22.91 & Increase \\
\hline 25.64 & 35.6 & 27.95 & Increase \\
\hline 25.65 & 28.9 & 0.83 & Increase \\
\hline 15.78 & 25.66 & 38.48 & Increase \\
\hline 12.65 & 20.15 & 37.19 & Increase \\
\hline
\end{tabular}

\section{Model Calibration}

In this section, by comparing the results of the physical model and numerical modeling to evaluate the increase or decrease of scour, the calibration of the model was performed and the results were validated. In Figure (11), a comparison is made between the results of the physical model in two rough and smooth crowns, with the results shown in Table (4). 


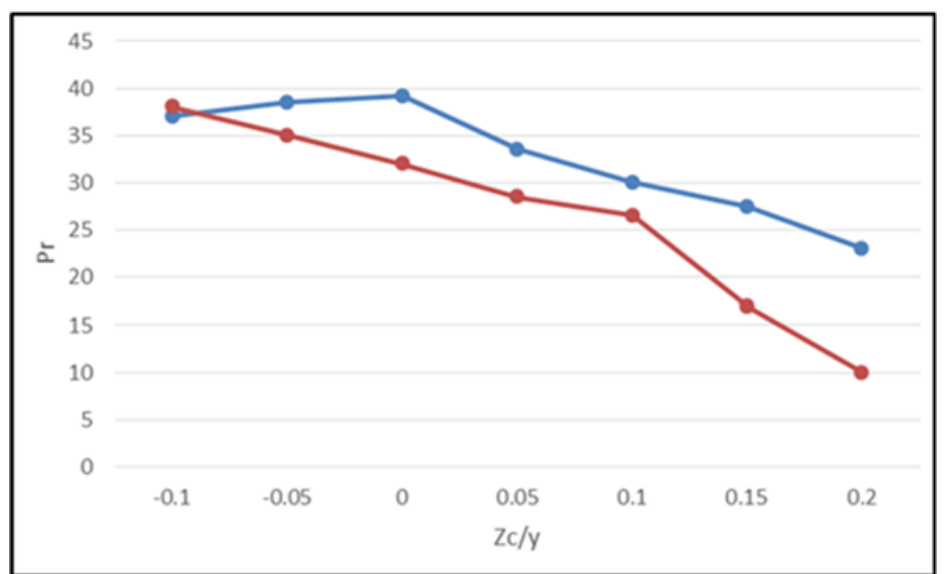

Fig 11. Comparison of the results in the case of smooth and coarse crowns in experimental condition

Table 4. Comparison of Laboratory Survey Results

\begin{tabular}{|c|c|c|}
\hline Difference (\%) & $\begin{array}{c}\text { Percentage of scour depth } \\
\text { decrease (rough crown) }\end{array}$ & $\begin{array}{c}\text { Percentage of scouring depth } \\
\text { decrease(smooth crown) }\end{array}$ \\
\hline $2 / 6$ & 38 & 37 \\
\hline 9 & 35 & $38 / 5$ \\
\hline $18 / 3$ & 32 & $39 / 2$ \\
\hline $14 / 9$ & $28 / 5$ & $33 / 5$ \\
\hline $11 / 6$ & $26 / 5$ & 30 \\
\hline $38 / 18$ & 17 & $27 / 5$ \\
\hline $56 / 52$ & 10 & 23 \\
\hline \multicolumn{3}{|c|}{} \\
\hline
\end{tabular}

Percentage of scour depth decrease (smooth crown) Percentage of scour depth decrease (rough crown) Difference (\%)Percentage difference $=24 / 79$. The results from Table (4) show that the mean scour depth reduction for laboratory modeling is about $24 \%$, while the numerical modeling results show the mean scour depth reduction of $22 \%$; We conclude that the numerical model results are reliable and in high confidence range.

\section{Conclusion}

Scour around the pier of bridges is one of the most important issues in hydraulics and sediment science.

Occurrence of local scour around the pier and brackets is one of the major causes of bridge failure, in that the crowns protect the bed against eddy currents around the pier and thus play a significant role in reducing the risks of scour in structures such as bridges. they do. Important results of numerical modeling in the present study are as follows:

- If crowns are close to the bed or under the bed, their performance and efficiency will be reduced and they will perform the same.

- If the crown is at a reasonable distance from the stable bed of sediment, it is a very effective structure to reduce scour around the bridge support. The results of applied diagrams on crown type and reduced depth of scour showed that rough crown due to faster change of boundary layer regime from slow to turbulent and thus delay in separation and even non-separation and consequently delay in recurrent flows and Even without it, it reduces the scour around the bridge support.

Investigation of flow field during crown mounting showed that crown has an effective role in reducing local scour by attenuating downstream flow and inhibiting early edges.

- The use of the crown on the cylindrical pier has been very effective in influencing flow turbulence and reducing erosion factors. The results also showed that the bridge pier with $0.5 \mathrm{~m}$ crown is the most suitable option for the pier crown length. In Figures (12) and (13), the changes in the scour depth and its abrupt increase in initial time and its decrease over the duration of the process are noticeable. It should be noted, however, that the approximate similarity of Figures (12) and (13) indicates that the position of the scour will no longer be at the foot of the pile; in other words, the scouring process will be transferred to the crown edges. 


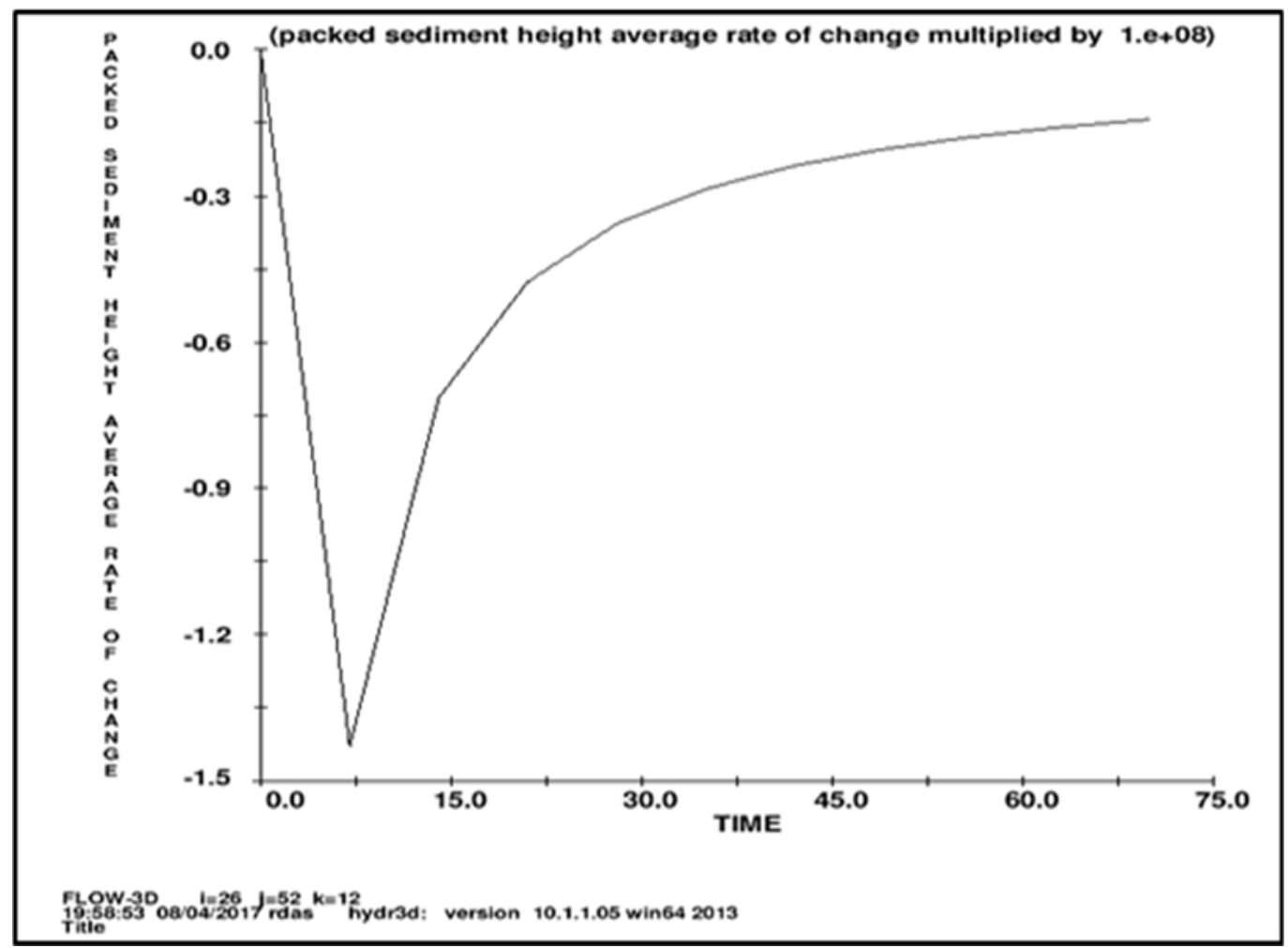

Fig 12. Chart of change of scour depth over time in the absence of crowns

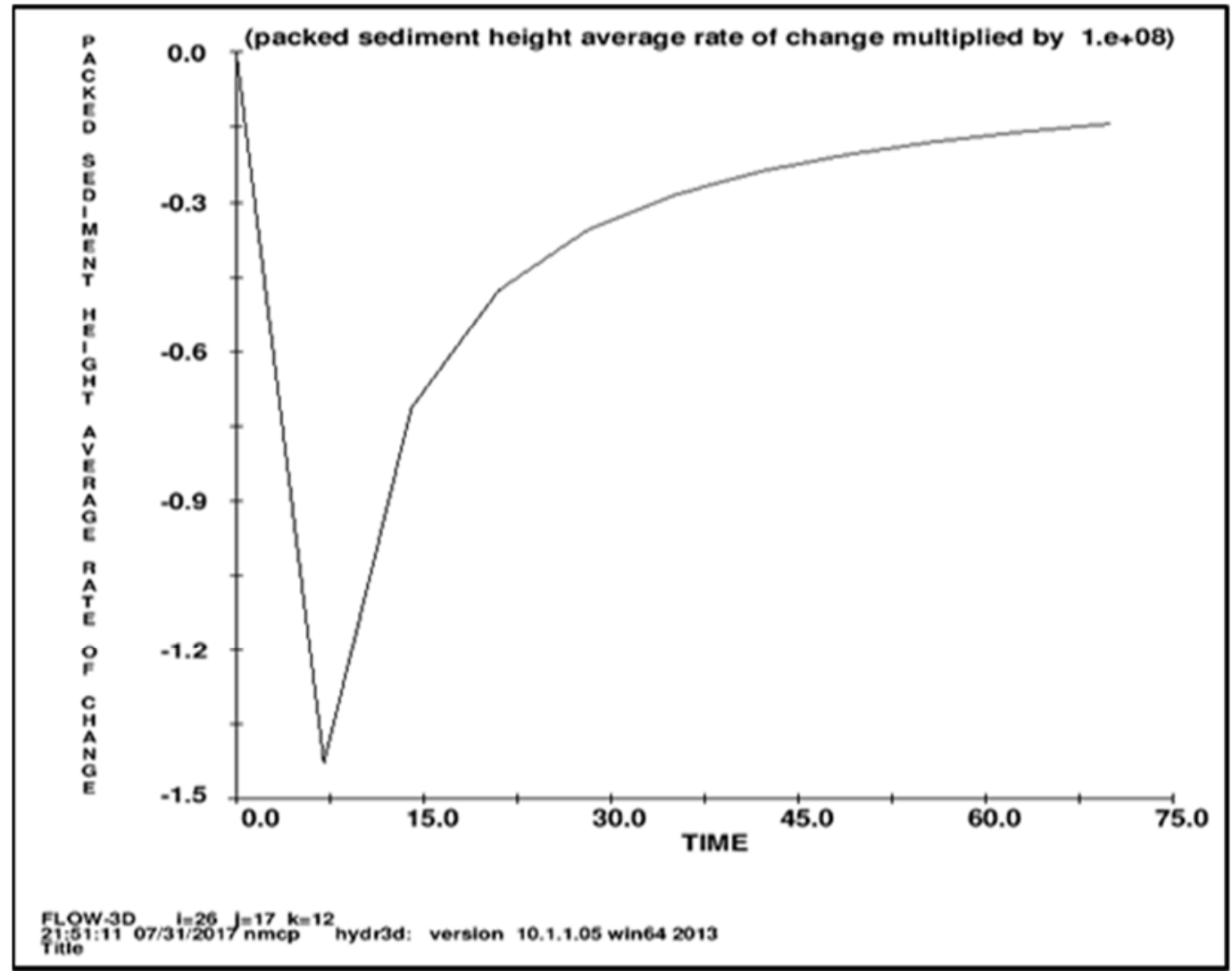

Fig 13. Depth of scour depth versus time under crown condition

- Increasing the dimensionless crown length from 0.5 to 0.75 which is $25 \%$ of the length of the crown increases the crown yield by about $2 \mathrm{x}$.

- By changing the smooth crown to rough crown by about $22 \%$, the reduction in scour increases and conditions improve. 


\section{Reference}

[1] Arianfar, AS and Shafaei Bojestan, M. (2016), "Investigation of shear stress distribution in slope bridge piers by FLUENT model," Iranian Hydraulic Conference, Shahid Abbaspour University of Water and Power Technology, Tehran, Iran.

[2] Ghorbani, B., and Kells, J. A. (2008). Effect of submerged vanes on the scour occurring at a cylindrical pier. Journal of Hydraulic Research, 46(5), 610-619.

[3] Mashahir, M. B., Zarrati, A. R., and Rezayi, M. J. (2004). Time development of scouring around a bridge pier protected by collar. In Proceedings 2nd International Conference on Scour and Erosion (ICSE-2). November 14.-17., 2004, Singapore.

[4] Nohani, E., Bejestan, M. S., Masjedi, A., and Kashkuli, H. A. (2012). Riprap Stability in the Vicinity of a Bridge Pier Fitted with a Collar in the Rivers Bend. World Applied Sciences Journal, 20(3), 354-358.

[5] Singh, C. P., Setia, B., and Verma, D. V. S. (2001). Collar-sleeve combination as a scour protection device around a circular pier. In PROCEEDINGS OF THE CONGRESS-INTERNATIONAL ASSOCIATION FOR HYDRAULIC RESEARCH (pp. 202-209).

[6] Zarrati, A. R., Gholami, H., and Mashahir, M. B. (2004). Application of collar to control scouring around rectangular bridge piers. Journal of Hydraulic Research, 42(1), 97-103. 